\title{
On strategies to improve student engagement
}

\section{M $^{a}$ Asun García ${ }^{1}$, Ana M. Valle ${ }^{2}$}

${ }^{1}$ Department of Mathematics, University of the Basque Country, Spain, ${ }^{2}$ Department of Applied Mathematics and Statistics and Operation Research, University of the Basque Country, Spain.

\begin{abstract}
After Bologna declaration, the change of roles between student and instructor in Spanish Higher Education has meant the search of new strategies to improve student engagement. In fact, they are trying to transform the previous extremely instructor-centred model to a learner-centred model. In this line, many courses of Higher Education have used new learning methods, such as problem-based learning, project-based learning or flipped classroom, during the last decade. Faculty also is able to count on new tools, for example, virtual classrooms. In this paper, we analyse the use of a virtual classroom in an elective course of the Degree in Mathematics at the University of the Basque Country to detect the assignments to improve student engagement and the impact on achievement of competences. We conclude that the inclusion of collaborative assignments in virtual classrooms increases their use and, hence, student engagement. Moreover, the acquisition of competences is also getting stronger, as the percentage of students that pass the course increases.
\end{abstract}

Keywords: Learner-centred learning; virtual classroom; student engagement. 


\section{Introduction}

Undergraduate degree programs adapted to European Higher Education Area bring along a high level of student engagement in learning-teaching process. This also implies to institutions, which have a duty to provide resources that promote it. Zepke \& Leach (2010) suggest that the engagement can act as a proxy for quality in education. Therefore, faculty has explored strategies to facilitate student engagement. In such a way, new learning methods, such as flipped classroom (Baepler et al. (2014)) have appeared. Moreover, other learning resources, for instance virtual classroom, have been widely used. In fact, many lecturers use virtual classroom as a supplement to face-to-face learning. Indeed, a new learning method emerged at the end of the 90's: the blended learning (Bonk \& Graham (2006), Rooney (2003)). It combines the benefits of face-to-face learning with the advantages of on-line learning, enabling to choose appropriate resources for each educational need (Moran (2012)). This blended learning, or b-learning, has spread quickly, due to not only the institutional support, but also learners and instructors has received it very well. For example, if we consider Degree in Mathematics at the University of the Basque Country, an 81.69\% of the courses uses virtual classroom as a supplement to face-to-face learning. Moreover, Means et al. (2013) analysed the effectiveness of online and blended learning. They showed a significant increase in performance with blended learning compared to face-to-face learning. However, they did not study factors that could influence in the positive results, such as additional learning time, instructional resources and encouragement of interaction among learners.

In this paper, we related the experience implemented in a virtual classroom as supplement to face-to-face learning for an elective course of the 4th year of Degree in Mathematics at the University of the Basque Country from the academic year 2015/16 to the academic year 2019/20. This virtual classroom has changed its design during these academic years, by adding/removing resources in order to facilitate student engagement and the acquisition of competencies. These changes have made it possible to identify activities that promote student engagement and improve their outcomes.

\section{Methodology}

\subsection{Experience framework}

As we have said, the course that we have developed the experience is Codes and Cryptography, an elective course of the 4th year of Degree in Mathematics at the University of the Basque Country. The number of credits ECTS for this course is 6 , which are divided in 3.6 ECTS of master lectures, 0.9 ECTS of classroom practices, 1.5 ECTS of computer practices and 0.6 ECTS of seminars. This course is given during the first quarter (from September to December) of each academic year. 
In the University of the Basque Country, their virtual classrooms as a supplement to face-toface learning use a learning management system based in Moodle (Cole \& Foster (2007)). As we have said, the virtual classroom for Codes and Cryptography has regularly added/removed resources to facilitate student engagement, because of continuous improvement. Thus, at the beginning of every academic year, the instructors develop tasks that learners complete and submit by virtual classroom, before the final exam. Until the academic year 2017/18, these tasks were related to computer works. During the two last academic year, in 2018/19 and 2019/20, collaborative work, which is done in seminar sessions, has been added to the virtual classroom.

\subsection{Participants}

Two hundred and twenty eight persons participate in this study. They are the enrolled students in Codes and Cryptography from the academic year 2015/16 to the academic year $2019 / 20$ (see Table 1). The average of enrolled students per academic year is 45.6 students and the standard deviation is 11.37 students. The fact of being enrolled only 26 students in $2017 / 18$ causes that the average and the standard deviation do not represent properly the set of experimental data. If we remove the observation of enrolled students in 2017/18, we obtain an average of 50.5 enrolled students per academic year and a standard deviation of 3.51.

Table 1. Number of enrolled students in the course Codes and Cryptography per academic year.

\begin{tabular}{cc}
\hline Academic year & \# Students \\
\hline $2015 / 16$ & 54 \\
$2016 / 17$ & 53 \\
$2017 / 18$ & 26 \\
$2018 / 19$ & 48 \\
$2019 / 20$ & 47 \\
TOTAL & $\mathbf{2 2 8}$ \\
\hline
\end{tabular}

Source: University of the Basque Country.

\subsection{Data analysis}

The virtual classroom as a supplement to face-to-face learning for Codes and Cryptography collects resources of a broad spectrum. Thus, it contains:

- General information useful for the student (Infor.), such as, teaching guide, tutorial schedule, task calendar, forum, links, exam templates, ordinary/extraordinary exam call, ... 
- $\quad$ Lecture notes (Lect.).

- Exercises and problems to solve (Exer.).

- Lecture note and exercises to solve during seminar sessions (Sem.).

- Papers related with the course (Other)

- Computer exercises to solve (Com.Exer.).

- Links to submit solved computer exercises (Submi.).

- Collaborative tasks (Col.), such as: wiki, database,...

Then, by using the activity report giving by the system, we have analysed the evolution of student activity, in order to detect the resources with higher activity than others. We have also calculated the achievement rate for ordinary call in each academic year and we have analysed whether the activity in the virtual classroom can influence the acquisition of specific competences or not.

\section{Results and Discussion}

The virtual classrooms at the University of the Basque Country give detailed activity reports, computed by the participants' logs. Instructors can receive these reports by student or by resource. If the instructor chooses "by resource", then the number of students and views to a particular resource appear in the activity report of that resource. We have obtained activity reports by resource for all resources of the virtual classroom yearly, from 2015/16 to 2019/20. Hereafter, we have classified all the resources that appear in the virtual classroom according to the above-named categories (see 2.3 Data analysis) and we have computed the total of views for each categories divided by the number of enrolled students in that academic year

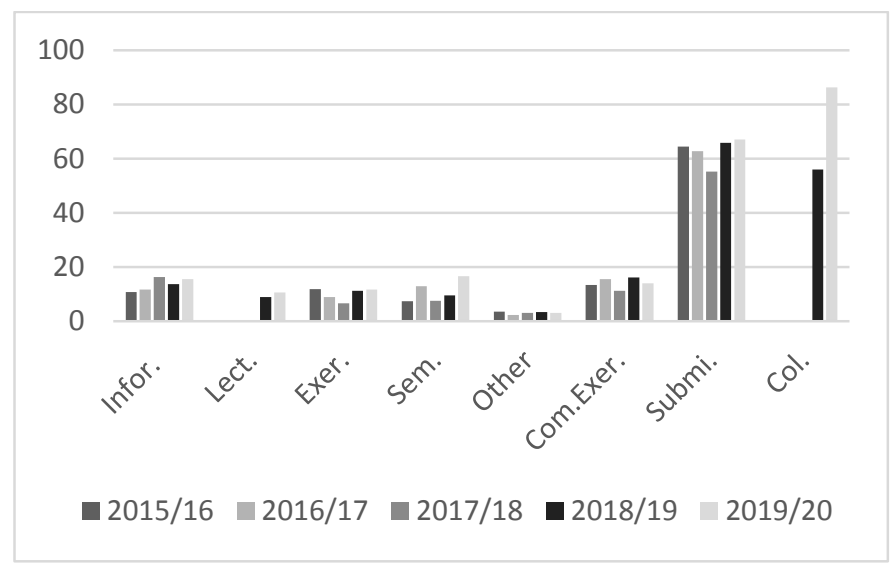

Figure 1. Activity per student and academic year. Source: Virtual classroom activity report from 2015/16 to 2019/20. University of the Basque Country. 
to obtain the average profile of student activity per academic year. Figure 1 shows the evolution of this average profile. Types of resources state in horizontal axis and the vertical axis gives the number of logs.

The resources in the virtual classroom change every academic year to encourage student engagement. During the first three academic year of this study, the resource with the highest activity was the submission of solved computer exercises. This submission use the assignment activity module of Moodle. Students submit individually files with programs implemented in Mathematica, which solve the proposed computer exercises. When reviewing assignments, teachers leave feedback comments and assignments are graded using a numerical scale. Final grades are recorded in the gradebook.

For the academic year 2018/19, we included two collaborative tasks, which were developed in seminar sessions. It was not compulsory to participate, but faculty recommended doing it. The first collaborative task used the database activity module of Moodle and the participants had to create, maintain and search a collection of entries (i.e. records) related with Codes and Cryptography. The teacher defined the structure of the entries as a number of fields. Field types included checkbox, radio buttons, dropdown menu, text area, URL and/or uploaded file. The second one used the wiki activity module of Moodle. The students added and edited a collection of web pages with the solutions of the exercises proposed in seminar sessions. It was defined as collaborative, with everyone being able to edit it. A history of previous versions of each page in the wiki was kept, listing the edits made by each participant. These two resources increased the student activity. Indeed, $100 \%$ of enrolled students participated in these two tasks.

However, we detected that the wiki implemented in our virtual classroom was not suitable to write mathematics and the students required excessive time to obtain a good result. Moreover, the use of the database was not as useful as we had planned, because students did not look for additional information in the references of the database. Thus, for the academic year 2019/20, we have changed these two collaborative tasks and we have used the workshop activity module of Moodle. The students, divided in groups of 4-6 students, submit the solution of exercises proposed in seminar sessions in a file. Students, using a multi-criteria assessment form defined by the teacher, assess submissions. The process of peer assessment and understanding the assessment form can be practised in advance with example submissions provided by the teacher, together with a reference assessment. Again, although it was not compulsory to participate, $100 \%$ of students have participated. To increase the acquisition of competences, the teacher has given feedback of the proposed solutions. Two thirds of the students have consulted this feedback. Moreover, this new collaborative task registers the highest activity in the virtual classroom during 2019/20 and it is a maximum of the data for average profile. Nevertheless, this activity has not influenced in the activity in 
the other categories. We also notice that the category with the lowest activity is "Other" during all academic years.

Furthermore, we have calculated the achievement rate per academic year for ordinary call (see Table 2). We notice that the inclusion of collaborative tasks in the virtual classroom can increase the acquisition of competences. Thus, the achievement rate has increased the last two years (see Table 2). Indeed, the rate in 2019/20 is the highest achievement rate.

Table 2. Achievement rate per academic year.

\begin{tabular}{cc}
\hline $\begin{array}{c}\text { Academic } \\
\text { year }\end{array}$ & $\begin{array}{c}\text { Achievement } \\
\text { rate }\end{array}$ \\
\hline $2015 / 16$ & $60 \%$ \\
$2016 / 17$ & $42.59 \%$ \\
$2017 / 18$ & $65.38 \%$ \\
$2018 / 19$ & $68.08 \%$ \\
$2019 / 20$ & $85.11 \%$ \\
\hline Source: University of the Basque Country.
\end{tabular}

\section{Guidelines for instructors to design an effective virtual classroom}

Based on authors' experience, few suggestions are proposed to make virtual classroom more effective:

- Include selected collaborative tasks in the virtual classroom to increase student engagement.

- Include resources with feedback or assessment to encourage student involvement.

- Include lecture notes, exercises and test or exam templates to facilitate student learning.

- Encourage the reading of additional lectures or papers by including an activity with student participation linked to them, such as a test or a short summary.

- A calendar with submission dates helps to plan student work. 


\section{Conclusions}

The main conclusions drawn from the analysis of the students' reports in the virtual classroom of the elective course Codes and Cryptography and their outcomes are the following ones:

- The resources that involve that students submit personal work (such as: submission of solved exercises, participation in wiki, and assessment of exercises,...) are the ones with higher activity in the virtual classroom.

- The information that is included in the virtual classroom, but it is not assessed (such as: papers, additional lectures, ...) does not generate interest among students.

- To include collaborative tasks in virtual classroom implies higher student engagement. However, student activity focuses on these tasks and it does not seem to be reflected in the activity registered in the other resources of the virtual classroom.

- The inclusion of collaborative tasks in the virtual classroom can increase the acquisition of competences and improve the achievement rate.

- A future action will be to include collaborative tasks in virtual classrooms for other courses and to compare them. Besides, the authors will design new activities related to the reading of papers and additional lectures to improve the students' interest for these resources.

\section{References}

Baepler, P., Walker, J. D., \& Driessen, M. (2014). It's Not About Seat Time: Blending, Flipping, and Efficiency in Active Learning Classroom. Computers \& Education, 78, 227-236.

Bonk, C. J., \& Graham, C. R. (2006). The Handbook of Blended Learning. San Francisco: Pfeiffer.

Cole, J., \& Foster, H. (2007). Using Moodle: Teaching with the popular open source course management system. Sebastopol: O'Reilly Media, Inc..

Means, B., Toyama, Y., Murphy, R., \& Baki, M. (2013). The effectiveness of online and blended learning: A meta-analysis of the empirical literature. Teachers College Record, 115(3), 1-47.

Morán, L. (2012). Blended-learning. Desafío y oportunidad para la educación actual. EDUTEC. Revista Electrónica de Tecnología Educativa, (39), a188, doi: 10.21556/edutec.2012.39.371

Rooney, J.E. (2003). Blending learning opportunities to enhance educational programming and meetings. Association Management, 55(5), 26-32. 
Zepke, N., \& Leach, L. (2010). Beyond hard outcomes: 'Soft' outcomes and engagement as student success. Teaching in Higher Education, 15(6), 661-673. doi: 10.1080/13562517. 2010.522084 . 